\title{
Corrosion Inhibition of Sabic Iron in Different Media Using Synthesized Sodium N-dodecyl Arginine Surfactant
}

\author{
A. Fawzy ${ }^{1,2, *}$, M. Abdallah ${ }^{1,3}$, M. Alfakeer ${ }^{4}, H . M . A l i^{5}$ \\ ${ }^{1}$ Chemistry Department, Faculty of Applied Science, Umm Al-Qura University, Makkah, Saudi \\ Arabia \\ ${ }^{2}$ Chemistry Department, Faculty of Science, Assiut University, Assiut, Egypt \\ ${ }^{3}$ Chemistry Department, Faculty of Science, Benha University, Benha, Egypt \\ ${ }^{4}$ Chemistry Department, Faculty of Science, Princess Nourah bint Abdulrahman University, Riyadh, \\ Saudi Arabia \\ ${ }^{5}$ Chemistry Department, Faculty of Science, Jouf University, Jouf, Saudi Arabia \\ *E-mail: afsaad13@yahoo.com
}

doi: $10.20964 / 2019.02 .08$

Received: 14 October 2018 / Accepted: 3 December 2018 / Published: 5 January 2019

\begin{abstract}
Sodium N-dodecyl arginine surfactant (sodium 2-(dodecylamino)-5-guanidinopentanoate) was synthesized and examined as an inhibitor for the corrosion of Sabic iron in acidic $(\mathrm{HCl})$, neutral $(\mathrm{NaCl})$ and alkaline $(\mathrm{NaOH})$ media using different techniques, namely, weight-loss (WL), potentiodynamic polarization (PP) and electrochemical impedance spectroscopy (EIS). Increasing the concentrations of the acidic, neutral and alkaline media increased the corrosion rates of Sabic iron and increased the corrosion rate in the order: $\mathrm{HCl} \gg \mathrm{NaCl}>\mathrm{NaOH}$. It was found that the inhibition efficiency of the inhibitor increased with the concentration of the inhibitor while decrease with raising temperature. The results indicate that the inhibition efficiency of the inhibitor increased in the studied media in the sequence: $\mathrm{HCl}>\mathrm{NaCl}>\mathrm{NaOH}$. The high inhibition efficiency of arginine surfactant inhibitor was interpreted on the basis of strong adsorption of the inhibitor molecules on the surface of Sabic iron and forming a protective film. The adsorption was found to obey Langmuir adsorption isotherm. The evaluated thermodynamic and kinetic parameters support the mechanism of physical adsorption of the inhibitor. The results obtained from all used techniques are in a good agreement with each others.
\end{abstract}

Keywords: Sabic iron, corrosion, sodium N-dodecyl arginine surfactant, inhibitor, adsorption.

\section{FULL TEXT}

(C) 2019 The Authors. Published by ESG (www.electrochemsci.org). This article is an open access article distributed under the terms and conditions of the Creative Commons Attribution license (http://creativecommons.org/licenses/by/4.0/). 